\title{
O USO PUBLICITÁRIO DO GIF ANIMADO MARCÁRIO
}

\section{The publicitary use of the animated trademarked GIF El uso publicitario del GIF animado para marcas}

\author{
Laura Cintra \\ Universidade de São Paulo, São Paulo, Brasil \\ Mestre pelo Programa de Pós-Graduação em Ciências da Comunicação da Escola de Comunicações e \\ Artes da Universidade de São Paulo (ECA-USP). E-mail: cintra.laura@gmail.com
}

\section{Sandra Souza}

Universidade de São Paulo, São Paulo, Brasil

Professora sênior e livre-docente da ECA-USP. E-mail: smrdsouz@gmail.com

RESUMO Este artigo apresenta o GIF animado como objeto de estudo, com ênfase nas capacidades técnicas e contribuições do formato para a comunicação publicitária na rede social Twitter. Fundamentado na abordagem semiótica de Charles Morris, o estudo propõe um método de análise nas dimensões sintática, semântica e pragmática e descreve publicações exemplares de três marcas selecionadas: Americanas.com, Coca-Cola e Salon Line. Com isto, objetiva-se situar distintas modalidades de uso marcário do GIF animado, bem como destacar suas potencialidades visuais e expressivas neste tipo de aplicação.

PALAVRAS-CHAVE GIF animado, Comunicação mediada, Publicidade, Semiótica.

ABSTRACT This article presents the animated GIF as study object, focusing on the technical capacities and contributions of the format for the advertising communication on the Twitter social network. Based on Charles Morris's semiotic approach, the study proposes an analysis method in the syntactic, semantic, and pragmatic dimensions and describes exemplary publications of three selected brands: Americanas.com, Coca-Cola, and Salon Line. Thus, we aim to place the distinct trademarked use modes of the animated GIF and highlight its visual and expressive potentialities in this kind of application.

KEYWORDS Animated GIF, Mediated communication, Publicity, Semiotics.

RESUMEN Este artículo presenta el GIF animado como objeto de estudio, haciendo hincapié en las capacidades técnicas y las aportaciones del formato a la comunicación publicitaria en la red social Twitter. Basándose en el enfoque semiótico de Charles Morris, el estudio propone un método de análisis en las dimensiones sintáctica, semántica y pragmática y describe publicaciones ejemplares de tres marcas seleccionadas: Americanas.com, Coca-Cola y Salon Line. Con ello, se pretende situar diferentes modalidades de uso del GIF animado por parte de las marcas, así como destacar sus potencialidades visuales y expresivas en este tipo de aplicaciones.

PALABRAS CLAVE GIF animado, Comunicación mediada, Publicidad, Semiótica.

\section{INTRODUÇÃO}

Em conjunto com as novas lógicas de compartilhamento e circulação de informações através de dispositivos móveis e redes sociais, novos formatos digitais passam a configurar a criação de discursos apoiados 
no aparato midiático. Dentre estes, o GIF animado constitui-se como um dos recursos disponíveis para a comunicação mediada por computador (Computer mediated communication $-C M C^{1}$ ) e, nesse sentido, atua como parte integrante dos sistemas representacionais específicos da rede, como os demais elementos das interfaces de interação com usuários.

Atualmente, o campo de estudo do objeto encontra-se guiado majoritariamente por três perspectivas: histórico-técnica (BAKHSHI et al., 2016; EPPINK, 2014; GYGLI, SOLEYMANI, 2016; JIANG, BRUBAKER, FIESLER, 2017; LI et al., 2016; NADAL, 2014; YANG, ZHANG, LUO, 2019); potencialidades expressivo-afetivas e narrativas (AMARAL, 2016; PEREIRA, 2018; SILVA, 2018); e design e literacia do formato (GÜRSIMSEK, 2016). Sob diferentes visões, todas também investigam as lógicas de aplicação dos GIF em termos de circulação e apropriação de conteúdo.

Ao iniciar nossa investigação, verificamos a amplitude ligada ao uso social dos GIF nos ambientes virtuais, aplicados a processos de comunicação interpessoal e institucional com finalidades específicas. Assim, estabelecemos nossa abordagem de investigação de maneira a conciliar aspectos técnicos, visuais e narrativos sob a caracterização das funcionalidades comunicacionais dos GIF animados, propondo um novo olhar sobre o objeto.

Utilizamos a semiótica tridimensional (MORRIS, 1985) com a avaliação de aspectos sintáticos, ou seja, relacionados aos elementos técnicos, composição visual e estruturas narrativas estabelecidas, semânticos associados aos sentidos atribuídos às narrativas apresentadas nas aplicações verificadas - e pragmáticos, isto é, ligados às funcionalidades e potencialidades expressivo-afetivas. A vertente de uso ligada à publicidade é nosso objeto de estudo: o uso marcário de GIF animados e suas associações com os aspectos comunicacionais desenvolvidos no contexto publicitário.

Este artigo analisa a incorporação de GIF animados na divulgação marcária por meio da análise de três marcas - Americanas.com², CocaCola $^{3}$ e Salon Line ${ }^{4}$ - que utilizam o formato no Twitter, de modos distintos. Esta plataforma digital foi uma das primeiras redes sociais a incluir o formato e apresenta o conceito de microblogging ${ }^{5}$. Notamos também que o Twitter oferece uma vasta gama de perfis verificáveis ${ }^{6}$ e permite a publicação de GIF animados nativos. Ademais, o emprego do formato é comum e recorrente em publicações diversificadas desta rede, inclusive de marcas.

Em relação à linguagem publicitária, discursos claros e concisos constituem, frequentemente, o tipo de comunicação mais efetiva para o desempenho das marcas. Com isto, o microblogging apresenta-se como tendência para a criação de canais de interação e suporte aos clientes, ocupando, em alguns casos, o posto de principal via de contato com o consumidor (QUESENBERRY, 2019). Esta observação é fundamental ao se pensar nas questões da construção da imagem da marca e da consolidação do perfil marcário, especialmente em relação ao uso de GIF animados.

1. O termo refere-se ao campo de estudo das interações comunicacionais realizadas a partir de computadores ou dispositivos digitais com lógicas de funcionamento semelhantes.

2. Disponível em: https://twitter.com/americanascom/. Acesso em: 5 maio 2021.

3. Disponível em: https://twitter.com/CocaCola_Br/. Acesso em: 5 maio 2021.

4. Disponível em: https://twitter.com/SalonLineBrasil/. Acesso em: 5 maio 2021.

5. Blog com limite de caracteres e publicações curtas.

6. A verificação de perfis fornecida pela própria rede social assegura a identidade do usuário, instituição ou marca. 
Cada uma das marcas avaliadas apresenta uma estratégia de produção de conteúdo publicitário específica que se utiliza do GIF animado como aspecto dominante das publicações analisadas neste estudo. A Americanas.com se apropria de GIF populares nos ambientes virtuais para apresentar suas ofertas; a Coca-Cola cria GIF próprios com predominância de suas cores identitárias e associa seus produtos a outras marcas ou fenômenos da cultura da internet, como franquias de restaurantes, influenciadores digitais e artistas, enquanto a Salon Line também produz seus próprios GIF, porém com ênfase na expressividade, gestualidade e bom humor das imagens utilizadas.

O período determinado para a extração de material que constitui o corpus desta pesquisa correspondeu a um mês, referindo-se ao intervalo das 0 h de 23 de junho de 2020 às 23 h59min59 de 22 de julho de 2020 . Foram coletadas, a partir do Twitter, 2209 publicações da Americanas. com (19,6\%), 2023 da Coca-Cola Brasil (17,9\%) e 7059 da Salon Line (62,5\%), totalizando 11291 tweets $^{7}$. Identificamos a ocorrência de 3096 GIF animados $(27,4 \%)$ e, deste total, 14 correspondem à Americanas. com (0,5\%), 1234 à Coca-Cola Brasil (39,9\%) e 1848 à Salon Line (59,7\%).

\section{TECNICIDADES E APLICAÇÕES DO FORMATO GIF}

A expressão GIF refere-se a um formato de imagem digital que apresenta parâmetros técnicos diferenciais, destacando-se a ausência de sonoridade e capacidade de visualização de movimentos dentro da imagem reprodutível. O acrônimo originou-se no nome técnico deste tipo de arquivo, graphic interchange format, ou formato intercambiável gráfico, em tradução livre, criado em 1987 pela CompuServe (EPPINK, 2014).

Os GIF estáticos podem ser designados simplesmente como imagem GIF, enquanto os GIF que denotam movimentos são denominados GIF animados. A reprodução de movimento presente nos GIF animados é cíclica, de modo que a repetição do conteúdo é constante. Este tipo de imagem tem ganhado notoriedade nos últimos anos, especialmente pela adaptação dos mecanismos de publicação de redes sociais populares para incorporação do formato.

Devido à sua peculiaridade cíclica, o GIF animado diferencia-se da imagem em movimento tradicional do cinema, vídeo ou televisão, caracterizando uma nova forma de transmissão, reprodução e apreensão de sentidos através da imagem em constante movimento. A repetição automática e ininterrupta do conteúdo estrutura uma espécie de comunicação visual que se reitera ao longo da observação, e o ciclo possibilita "a leitura de novas camadas de sentido, construídas a cada período” (NADAL, 2014, p. 162).

\section{ASPECTOS DA COMUNICAÇÃO MEDIADA}

Em termos gerais, as comunicações mediadas por computador ou CMC são dotadas de caráter impessoal devido à reduzida personalização oriunda de sua instrumentalidade (WALTHER, 1996). Contudo, informações não verbais auxiliam na apreensão de sentido (JIANG; BRUBACKER; FIESLER, 2017), preenchendo lacunas de significação que a comunicação interpessoal não mediada pode oferecer em termos de, por exemplo, tom de voz ou gestualidade.

7. Publicações realizadas via Twitter. 
Os GIF animados são elementos visuais integrantes das comunicações mediadas por computadores e dispositivos móveis e, apesar de serem reconhecidos por seu uso interpessoal, têm sido utilizados em domínios oficiais de marcas nas redes sociais com o intuito de chamar atenção de internautas para redirecioná-los a aplicativos de venda ou páginas de comércio eletrônico e favorecer o engajamento de possíveis consumidores por meio de interações baseadas nos conteúdos apresentados pelas imagens.

Esta prática é oriunda da transição de uma lógica de publicização vertical para um modelo horizontal que inclui os consumidores através da esfera social (KOTLER; KARTAJAYA; SETIAWAN, 2017). Isto também ocorre dentro das redes sociais, dado que "no novo modelo de colaboração do consumidor, as empresas tornam-se um centro para o fluxo constante de discussão da marca” (QUESENSBERRY, 2019, p. 43, tradução nossa). A importância do uso do GIF animado relaciona-se ao seu poder de engajamento dentro das redes sociais.

De acordo com Bakhshi et al. (2016), o formato é engajador, isto é, tem uma taxa de interações acima da média quando comparado com outros tipos de imagem, por três fatores: consumo de banda reduzido, ausência de sonoridade e baixo grau de comprometimento de banda e atenção. Desta forma, os usuários das redes conseguem visualizar o conteúdo com pouco impacto no consumo de internet, têm facilidade em compreender as imagens sem necessidade de uso de dispositivos de áudio, além de uma combinação destes fatores, que torna o entendimento dos GIF acessível em diferentes modos e locais de acesso. Nosso objetivo é demonstrar distintas modalidades de uso marcário do GIF animado e, desta forma, destacar as potencialidades visuais e expressivas do formato neste tipo de aplicação publicitária.

Por exemplo, um GIF animado marcário pode ilustrar promoções, tendo caráter estritamente relacionado à divulgação de uma oferta específica. Na Figura 1, a Coca-Cola Brasil oferece cupom de desconto para compra de produtos Coca-Cola no restaurante McDonald's através do aplicativo Rappi. Ainda dentro do contexto publicitário, o objeto pode ser utilizado como expressão da marca, na qual a função básica da imagem é a aproximação com a gestualidade e sensibilidade dos interlocutores, como apresentado na Figura 2, em que a Salon Line cria uma publicação com um texto que é ironicamente complementado pela inserção do GIF.

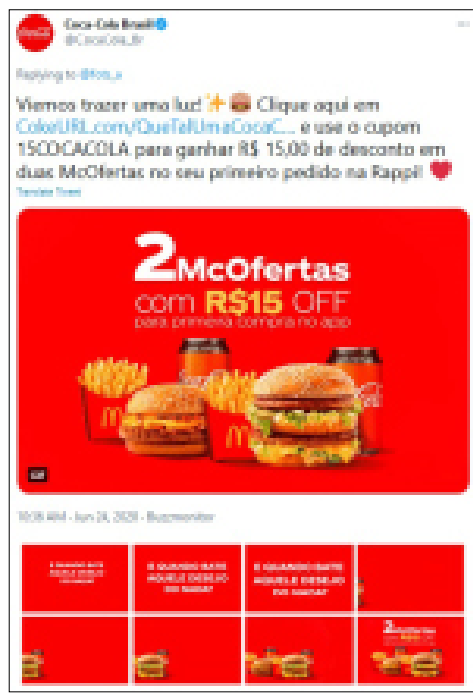

Figura 1. GIF animado utilizado pela Coca-Cola Brasil

Fonte: Twitter Coca-Cola Brasil.

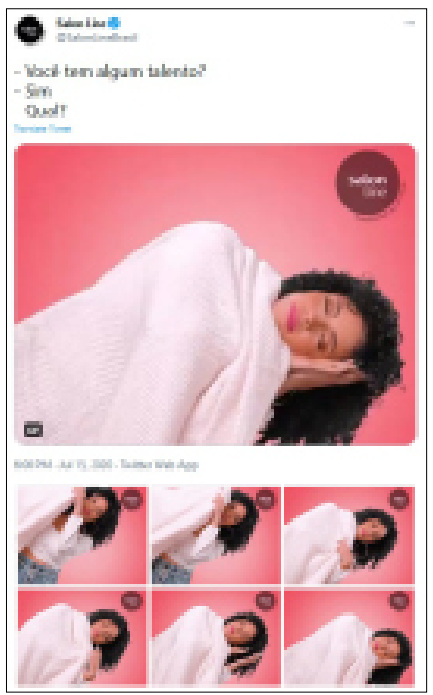

Figura 2. GIF animado utilizado pela Salon Line

Fonte: Twitter Salon Line. 


\section{METODOLOGIA DE ANÁLISE DE GIF ANIMADOS PUBLICITÁRIOS}

$\mathrm{Na}$ linguagem escrita, os termos estabelecem relações entre si, e a estrutura sintática é a interrelação de signos causada pela interrelação de respostas das quais os veículos sígnicos são produtos ou partes e que os modos de uso constituem o quadro pragmático (MORRIS, 1985). De modo análogo, percebemos que os principais elementos da composição e da montagem de obras audiovisuais se constituem a partir das associações entre elementos gráficos, planos, volumes, espaços, iluminação e tempo (EISENSTEIN, 1977) e se aplicam à análise do conteúdo de GIF animados, essencialmente imagens em movimento de repetição cíclica. Com isto, a dimensão sintática de análise abrange os elementos constituintes que se modificam e se complementam dentro da unidade gifian $a^{8}$. As principais características sintáticas do GIF animado concentram-se no tipo de repetição, temporalidade e estética apresentadas.

O ciclo de repetição pode ser imperceptível (repetitividade contínua) ou apresentar descontinuidades, sendo perceptível o início e final das ações (repetitividade descontínua). A temporalidade destas imagens associa-se à estrutura temporal-narrativa, que pode ser circular (quando contínua) e linear (quando descontínua). Ainda dentro deste quesito, observamos possibilidades narrativas oriundas dos estágios dramáticos (BREMOND; CANCALON, 2014), que consistem, no caso dos GIF, na evolução (com progressão) ou estagnação (sem progressão) do estado narrativo. Dentro do âmbito estético, percebemos os elementos visuais em si, como citado anteriormente, que podem ser divididos entre tipo de registro (animação, live action ou híbrido), composição (enquadramento, movimentos de câmera, montagem) e estilo (cor, formas, linhas, tipografia).

A dimensão semântica identifica relações de sentido criadas a partir da aplicação do GIF animado no processo comunicacional marcário. As relações entre GIF animado e os parâmetros visuais estruturantes de marca são destacados, dado que entropia marcária é um sistema organizado cujos elementos constitutivos, inclusive a publicidade, lhe dão sustentação (PEREZ, 2004), passando pela perspectiva de seus signos visuais.

A marca pode construir sua identidade sob quatro perspectivas distintas. Em relação aos seus produtos, visa criar ligações diretas com a experiência de uso e escolha do consumidor; como organização, elabora sua identidade pela expressão de seus valores organizacionais; na qualidade de pessoa, estabelece uma personalidade e cria relações com seus consumidores; e, enquanto símbolo, utiliza-se de recursos visuais e metáforas que lhe atribuam identidade (AAKER, 1996).

As relações semânticas estabelecidas podem ser de complementaridade, contradição, exacerbação ou personificação do discurso marcário e foram previamente reconhecidas a partir da análise do material de estudo. Basicamente, a averiguação semântica tem como intuito verificar as associações entre estruturas de identidade de marca e as atribuições de sentido através das imagens em formato GIF utilizadas em publicações no corpus coletado do Twitter.

Não obstante, a utilização de GIF animados sempre precede uma finalidade específica, algum intuito funcional ligado ao seu emprego. A priori, a função publicitária é destacada pelo recorte estabelecido para esta pesquisa, centrada no estudo dos GIF animados em contexto marcário. Entretanto, o uso das imagens não se limita a um único papel, mas a uma

8. Própria ou relativa aos GIF animados. 
complexa cadeia em que diferentes funções se encontram entremeadas. Em outras palavras, um GIF animado pode ter como principal função a divulgação publicitária, mas também apresentar potencial para informar, entreter, expressar e decorar, categorias do uso social de GIF animados (CINTRA; SOUZA, 2020). Apresentamos a seguir o resumo do levantamento de elementos a serem analisados em cada dimensão proposta (Figura 3).

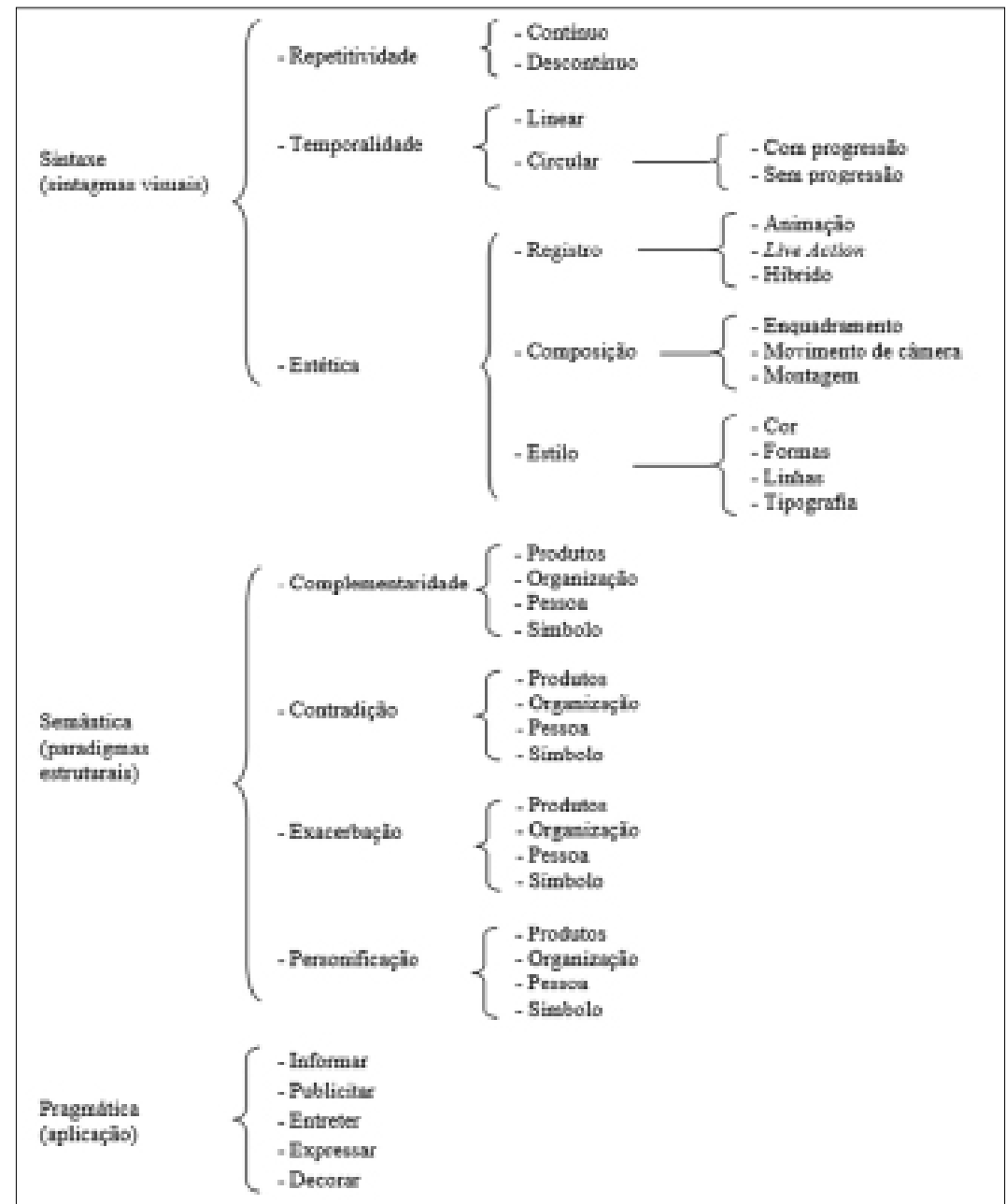

Figura 3. Modelo esquemático de análise semiótica tridimensional

Fonte: Cintra e Souza (2020).

\section{OS GIF ANIMADOS EM PRÁTICAS PUBLICITÁRIAS}

A abordagem da Americanas.com é caracterizada pelo uso do humor e aplicação do GIF animado em complementaridade ao texto promocional publicado pela marca em sua timeline 9 . A Figura 4 apresenta a apropriação de um GIF não marcário, desvinculando o tweet do aspecto estritamente publicitário e aproximando-se de um perfil pessoal do Twitter. Entretanto, o texto divulga a promoção e conta com link para direcionar os usuários da rede social para a plataforma de comércio digital.

9. Listagem das publicações do perfil do usuário ou publicações ordenadas para visualização ao acessar as redes sociais. 


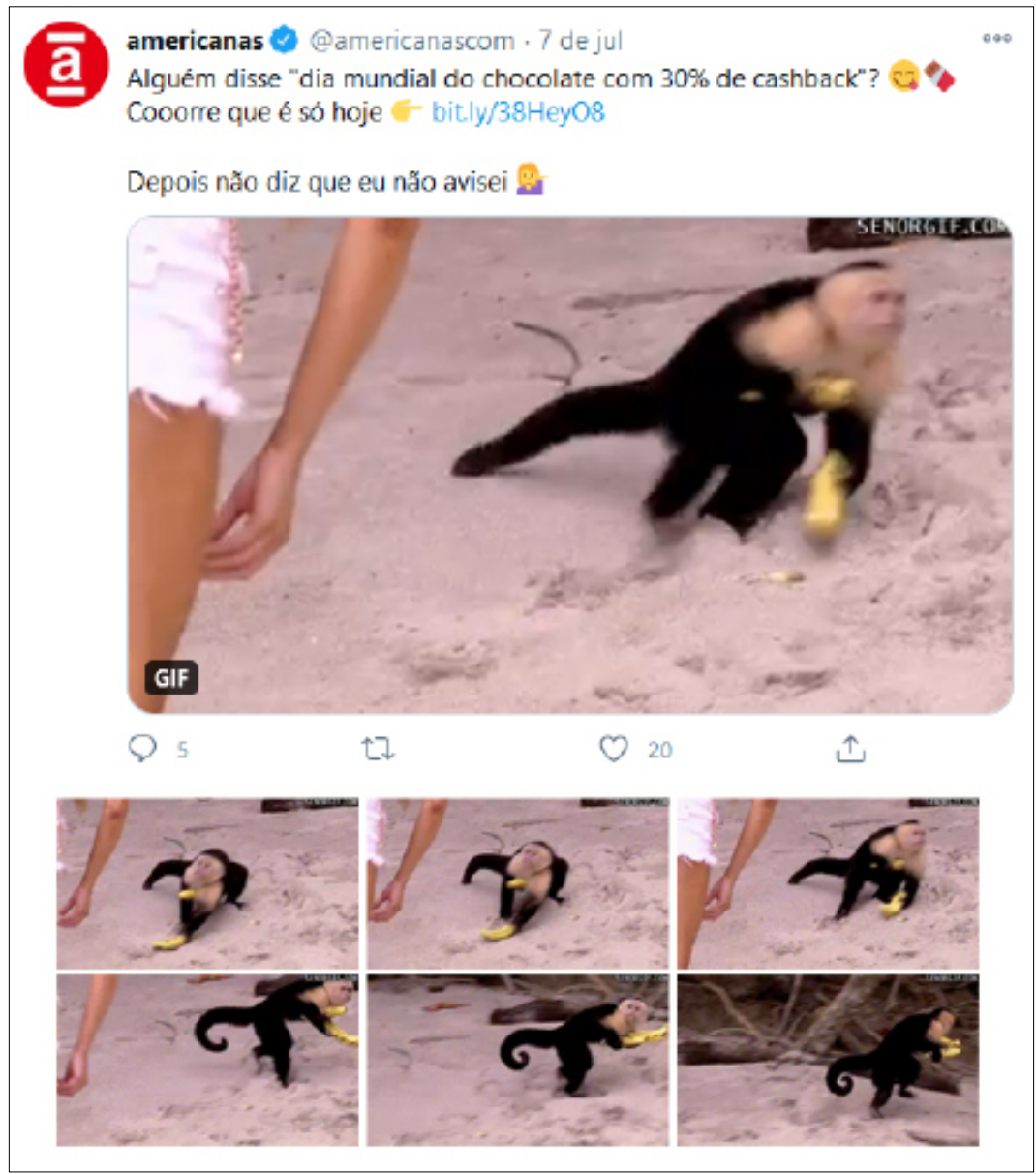

Figura 4. GIF animado utilizado pela Americanas.com.

Fonte: Twitter Americanas.com

O GIF é descontínuo e de temporalidade linear. Com a repetição automática do conteúdo, é possível identificar o momento em que a ação termina e recomeça, com evolução bem definida. Na narrativa apresentada, um pequeno símio rouba uma banana e sai para se esconder. o registro é live action, possivelmente adaptado de vídeo amador, com movimento de câmera para acompanhar a ação da personagem principal, o macaco. A manipulação do enquadramento rememora o uso cinematográfico da câmera na mão, recurso notório para atribuição de espontaneidade em filmes, o que corrobora o tom humorístico da imagem.

Em relação à carga semântica, o GIF atua em dupla camada de significação. Primeiramente, em complementaridade ao texto promocional, realizada através da metáfora bem-humorada do comportamento humano perante uma oferta limitada, agindo de maneira rápida e fortuita para garantir a compra dos bens desejados dentro do período limitado. Também se observa a personificação do animal presente na imagem, agregando leveza à identidade da marca construída no Twitter.

A pragmática neste exemplo é publicitária, estampando o anúncio promocional, mas notamos a expressão do comportamento humano através da personificação do macaco, promovendo entretenimento em tom humorístico que busca cativar o consumidor. Nesse sentido, a publicização passa não somente pela perspectiva de aquisição do produto em promoção, mas também pelo viés do consumo de conteúdo digital em formato de GIF animado disponibilizado pela marca. 
A Coca-Cola Brasil parte para outra estratégia de uso publicitário do GIF animado (Figura 4), com aplicação de um GIF animado temático criado pela marca para divulgação do evento \#CokeStudioSessions, cuja principal atração foi a apresentação da cantora Katy Perry. Este exemplo consiste em uma resposta à publicação publicitária patrocinada, denotada pelo uso da hashtag ${ }^{10} \# a d$, feita por Maísa, personalidade da televisão brasileira e influenciadora digital. A Coca-Cola Brasil interage com Maísa em tom informal, como num diálogo entre amigas, utilizando um GIF animado. De autoria própria, o conteúdo utiliza as cores características da marca e a inserção de embalagens de seu produto.

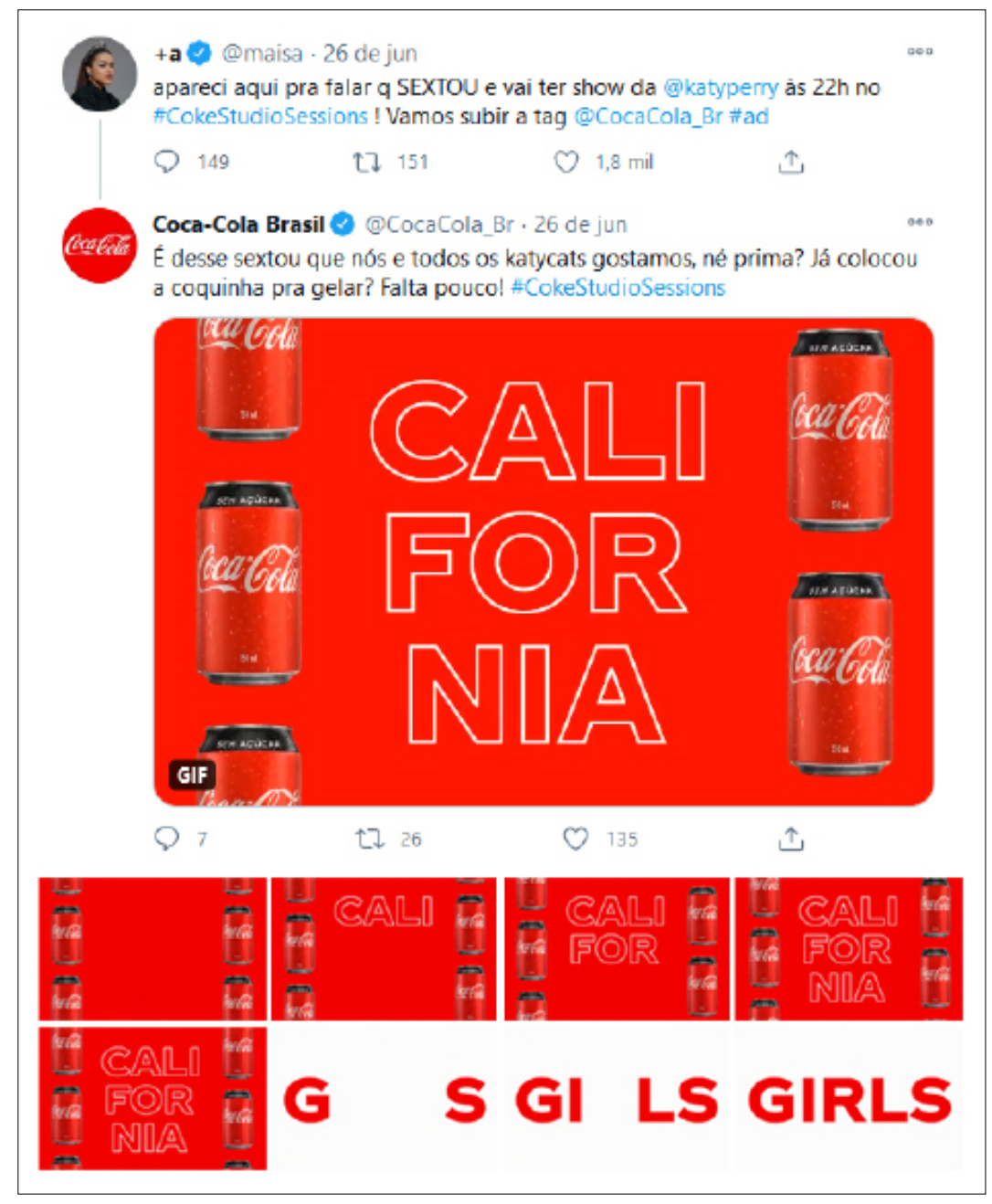

Figura 5. GIF animado utilizado pela Coca-Cola Brasil

Fonte: Twitter Coca-Cola Brasil.

O GIF apresentado é contínuo e circular, sem progressão narrativa. Isto é, não existem alterações ou evoluções dramáticas no decorrer do conteúdo, que se trata de uma animação de letreiros. Neste caso, a circularidade reside no fato de que o início ou o final da ação não são relevantes, dado que não existe um desenvolvimento narrativo. No primeiro plano do GIF,

10. Palavras-chave associadas a assuntos ou tópicos de discussão indexados de forma explícita através do uso da cerquilha (\#) em redes sociais. 
encontram-se fotografias de produtos Coca-Cola inseridas nas margens direita e esquerda, e ao centro observa-se a formação da palavra California sobre o fundo vermelho. Em seguida, o fundo passa a ser branco e identificamos a composição da palavra Girls. Os letreiros referem-se ao título de uma das canções de Katy Perry, “California Gurls”.

A complementaridade é a vertente semântica observada e ocorre em três níveis distintos. A imagem complementa o sentido da organização da marca, associando-a ao evento musical promovido. Num segundo nível, cria uma relação com a identidade da marca, conectando-a aos fãs da cantora. Ademais, reitera a presença da marca pela inserção de seus produtos e símbolos dentro do GIF animado.

A pragmática de publicização é dominante e o GIF animado reitera a identidade visual, produtos e símbolos da marca, associando a Coca-Cola a fenômenos de audiência jovem nas plataformas digitais. Seu conteúdo, entretanto, tem também a função de entreter, com uma animação arrojada, e observa-se o apelo decorativo da imagem. Com tipografia característica e cores vibrantes, este tipo de GIF adorna a publicação e pode exercer o papel de adereço em tweets de fãs da cantora.

Por outro lado, a Salon Line produz seu conteúdo recriando características de GIF de reação ${ }^{11}$, carregados de expressividade e gestualidade. Este tipo de imagem tornou-se popular na comunicação em ambientes virtuais e, ao apropriar-se do fenômeno para conceber seu material, a marca parte para representação de reações comuns de usuários das redes sociais e de consumidores de seus produtos. Demonstrando entendimento do uso social de GIF animados, a Salon Line diferencia seu conteúdo de maneira inovadora, auxiliando na consolidação da identidade da marca no Twitter, caracterizada pela criatividade e irreverência.

Na Figura 6, a marca descreve textualmente uma ação, o ato de sentir o aroma de produtos antes de utilizá-los, e apresenta uma mulher, enrolada em toalhas, cheirando um pote de creme da Salon Line. O GIF é descontínuo e linear com progressão, e utiliza-se de uma estética live action e de enquadramento fixo. No decorrer da ação, a jovem muda sua expressão de distraída para extasiada ao experienciar o perfume do produto, denotando alteração do estado dramático da personagem e atribuindo progressão narrativa à imagem. A paleta de cores dialoga com o produto, presente na cena, e também observamos a inserção da logomarca no canto superior direito da imagem.

Através de uma relação semântica de complementaridade, tanto em relação ao texto, que descreve a ação visualizada no GIF, quanto em relação à descrição de um suposto comportamento da marca (denotado pelo uso do pronome "eu"), a Salon Line se identifica com seus consumidores. Encontramos a mesma dinâmica em relação à logomarca e aos produtos, presentes na imagem.

A pragmática publicitária destaca-se pelo caráter imbuído na publicação em perfil marcário e utilização da logomarca da Salon Line em seu conteúdo. Entretanto, a iconicidade da ação representada tem também função expressiva e permite que a imagem seja apropriada por outros usuários das redes sociais. Da mesma forma, o GIF animado também serve ao propósito de entreter, com o bom humor característico do uso do GIF de reação, promovendo a aproximação da marca com seu público.

11. Aplicação de GIF animados como resposta, substituindo texto escrito (AMARAL, 2016) com o intuito de expressar emoções (EPPINK, 2014). 
Eu cheirando meus creminhos antes de usar. Translate Tweet

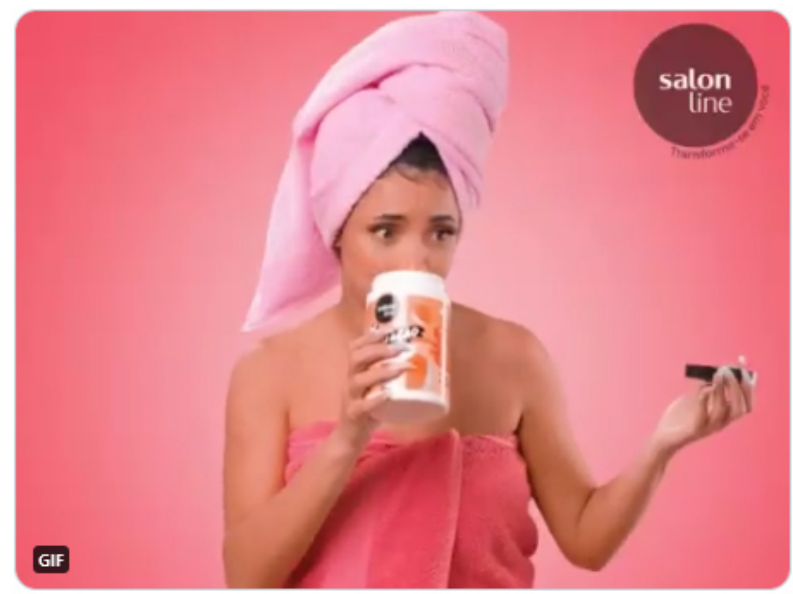

4:00 PM - Jul 3, 2020 - Twitter Web App

55 Retweets 7 Quote Tweets 197 Likes
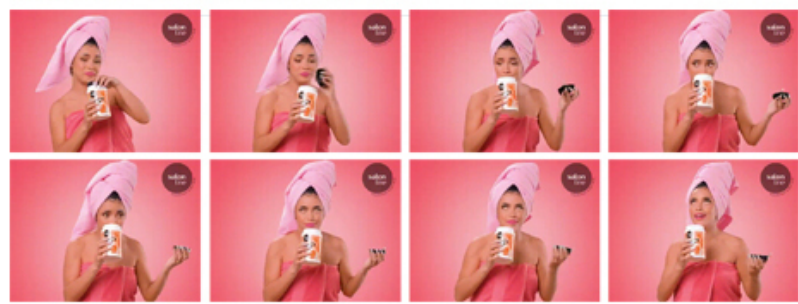

Figura 6. Tweet com GIF animado da Salon Line.

Fonte: Twitter Salon Line.

\section{CONSIDERAÇÕES FINAIS}

O uso social de GIF animados nas comunicações mediadas por computador ou dispositivos eletrônicos é uma forma rápida e simples de compartilhar conteúdo através da internet, em especial, nas redes sociais. As características técnicas propiciam a difusão do formato, enquanto as potencialidades narrativas do GIF animado podem ser exploradas de modos distintos de acordo com os intuitos dos usuários.

Apesar das distinções observadas nas estruturas de emprego dos GIF animados, todas as marcas observadas utilizaram-se da complementaridade semântica como modo de encaixar o formato em suas publicações. Para além da ilustração de processos de consumo representados no conteúdo das imagens ou da exploração de símbolos de marca, existe potencial para o estabelecimento de significações em camadas secundárias, se observados aspectos sintáticos e pragmáticos.

Também verificamos a existência de duas linhas de criação possíveis para GIF animados originais de marca. A primeira delas é a concepção de imagens puramente promocionais, que apresentam produtos e divulgam ofertas. A segunda opção refere-se à elaboração de GIF animados que contêm elementos da cultura das redes sociais, constatada apenas nos GIF animados de reação da Salon Line. 
A apropriação de GIF oriundos de produtos culturais como filmes, animações e séries, bem como daqueles provenientes de vídeos amadores, é realizada com o intuito de complementar e ilustrar as publicações de marca. Também percebemos, nestes casos, a função de entreter os usuários com os quais os perfis marcários interagem no ambiente virtual do Twitter, como no caso da Americanas.com.

Em termos de apresentação dos símbolos da marca e reiteração de sua identidade visual, a Coca-Cola Brasil destaca-se pela coesão do material coletado para estudo. Utilizando sempre a mesma paleta de cores e tipografia, além de aplicações da logomarca e produtos com referências a parcerias, como McDonald's e Katy Perry, identifica-se com facilidade que o conteúdo se trata de comunicação marcária da Coca-Cola Brasil. A aplicação consistente do formato não abre margem para ambiguidade, o que pode ser negativo para a consolidação marcária em ambientes virtuais.

Por outro lado, o domínio do uso social de GIF animados demonstrado pela Salon Line auxilia na construção da identidade da marca enquanto pessoa, criando um relacionamento positivo com seus seguidores e potenciais clientes. Ainda que os símbolos ou produtos da marca não se encontrem em destaque, o sentido da marca é caracterizado pelo cuidado da comunicação com seus consumidores, fortalecendo o marketing de relacionamento.

Por fim, a Americanas.com utiliza-se de GIF animados de maneira esparsa, tal como a aplicação de outros formatos de imagem. Este comportamento indica que a marca preza menos pelo apelo visual do conteúdo de suas publicações do que pela ocupação do espaço fornecido pelo Twitter como um canal adicional de comunicação, majoritariamente via texto, com seus consumidores. Entretanto, a aplicação ocasional de GIF animados populares, apropriados de outros contextos, tem potencial para chamar atenção para marca.

\section{REFERÊNCIAS BIBLIOGRÁFICAS}

AAKER, David. Building strong brands. New York: The Free Press, 1996.

AMARAL, Ludmila Lupinacci. As apropriações do GIF animado: aspectos culturais, expressivos e afetivos dos usos de uma tecnologia defasada. Dissertação (Mestrado em Comunicação e Informação) - Universidade Federal do Rio Grande do Sul, Porto Alegre, 2016.

BAKHSHI, Saeideh; SHAMMA, David A.; KENNEDY, Lyndon; SONG, Yale; JUAN, Paloma de; KAYE, Joseph. Fast, cheap, and good: why animated GIFs engage us. In: CONFERENCE ON HUMAN FACTORS IN COMPUTING, 16., San José. Proceedings [...]. San José: SIGCHI, 2016. DOI: http://dx.doi.org/10.1145/2858036.2858532

BREMOND, Claude; CANCALON, Elaine D. The logic of narrative possibilities. New Literary History, Baltimore, v. 11, n. 3, p. 387-411, 2014.

CINTRA, Laura; SOUZA, Sandra. O uso de GIFS Animados como forma de representação e expressão nas redes sociais. In: CONGRESSO BRASILEIRO DE CIÊNCIAS DA COMUNICAÇÃO, 43., 2020, Salvador. Anais [...]. Salvador: UFBA, 2020.

EISENSTEIN, Sergei. Film form: essays in film theory. New York: Harvest: HBJ Book, 1977.

EPPINK, Jason. A brief history of the GIF (so far). Journal of Visual Culture, London, v. 13, n. 3, p. 298-306, 2014. DOI: https://doi.org/10.1177/1470412914553365.

GÜRSIMSEK, Ödül Akyapi. Animated GIFs as vernacular graphic design: producing Tumblr blogs. Visual Comunication, London, v. 15, n. 3, p. 329-349, 2016. DOI: https://doi.org/ $10.1177 / 1470357216645481$

GYGLI, Michael; SOLEYMANI, Mohammad. Analyzing and predcting GIF interestingness. In: ASSOCIATION FOR COMPUTING MACHINERY MULTIMEDIA CONFERENCE, 16., 2016 Amsterdam. Proceedings [...]. Amsterdam: ACM, 2016. p. 122-126. DOI: http://dx.doi.org/ 10.1145/2964284.2967195. 
JIANG, Jialun Aaron; BRUBAKER, Jed R.; FIESLER, Casey. Understanding diverse interpretation of animated GIFs. In: CONFERENCE ON HUMAN FACTORS IN COMPUTING SYSTEMS, 17., 2017, Denver. Proceedings [...]. Denver: ACM, 2017. DOI: http://dx.doi.org/ 10.1145/3027063.3053139.

KOTLER, Philip; KARTAJAYA, Hermawan; SETIAWAN, Iwan. Marketing 4.0: do tradicional ao digital. Rio de Janeiro: Sextante, 2017.

LI, Yuncheng; SONG, Yale; CAO, Liangliang; TETREAULT, Joel; GOLDBERG, Larry; JAIMES, Alejandro; LUO, Jiebo. TGIF: a new dataset and benchmark on animated GIF description. CVRP, Ithaca, arXiv:1604.02748v2 [cs.CV], 2016.

MORRIS, Charles. Fundamentos de la teoría de los signos. Barcelona: Paidós, 1985.

NADAL, João Henrique Duarte. A cultura do GIF: reconfigurações de imagens técnicas a partir dos usos e apropriações de narrativas cíclicas. Dissertação (Mestrado em Comunicação e Linguagens) - Universidade Tuiuti do Paraná, Curitiba, 2014.

PEREIRA, Francine de Almeida. Conto-te em pílulas de digital media: o GIF como nanonarrativa visual digital contemporânea. Dissertação (Mestrado em Estudo de Linguagem) Universidade do Estado da Bahia, Salvador, 2018.

PEREZ, Clotilde. Signos da marca: expressividade e sensorialidade. São Paulo: Cengage Learning, 2004.

QUESENBERRY, K. Social Media Strategy: Marketing, Advertising, and Public Relations in the Consumer Revolution. Lanham: Rowman \& Littlefield Publishers, 2019.

SILVA, F. S. Da origem no cinema à adaptação do GIF: transformações em circuito entre a produção de Pulp Fiction e o reconhecimento em confused Travolta. 2018. Dissertação (Mestrado em Ciências da Comunicação) - Universidade do Vale do Rio dos Sinos, São Leopoldo, 2018.

WALTHER, Joseph B. Computer-mediated communication: impersonal, interpersonal, and hyperpersonal interaction. Communication Research, London, v. 23, n. 1, p. 3-43, 1996 DOI: https://doi.org/10.1177/009365096023001001.

YANG, Zhengyuan; ZHANG, Yixuan; LUO, Jiebo. Human-centered emotion recognition in animated GIFs. In: INTERNATIONAL CONFERENCE ON MULTIMEDIA AND EXPO, 20., 2019, Shanghai. Proceedings [...]. Shanghai: IEEE, 2019. DOI: https://doi.org/10.1109/ ICME.2019.00191. 